\title{
An internet-based intervention program for supporting families with prematurely born infants
}

\author{
Birgitta Lindberg, Kerstin Öhrling \\ Department of Health Science, Luleå University of Technology, Luleå, Sweden \\ Email: birgitta.lindberg@ltu.se
}

Received 26 November 2011; revised 30 January 2012; accepted 20 February 2012

\begin{abstract}
The purpose of this paper was to describe the development, planning and implementing of an internetbased intervention program for providing support to families with prematurely born infants. During the families initial stay at home with their infant; families were given access to use of videoconference system from their home to have contact with staff at the neonatal unit, via direct link, throughout twenty-four hours. This program successfully ended, and videoconferencing is incorporated as a tool to support families after coming home. Probably, a variety of factors has contributed to make this program successful, as for example user friendliness and the close collaboration between researchers and staff at the neonatal unit. In conclusion, Information and Communication Technology (ICT) must be taken into consideration in developing upcoming care, thereby making possible a program to extend accessibility to health care.
\end{abstract}

Keywords: Intervention Program; Preterm Born; Support; Videoconferencing

\section{INTRODUCTION}

Parents of infants born prematurely have to face many stressors related to having a preterm infant. When it is time for the parents to go home with their infant, new demands and increased parental responsibility are created. To be able to manage and feel confident about bonding to and caring for their infants, parents have great needs for various kinds of support. Thereby, parents need to be supported by skilled personnel, with expert knowledge in medical, technical, and nursing care. An intervention study was thus designed and implemented to ascertain if real-time videoconferencing can be used as a tool to improve support to parents.

The parenting role is different for parents of premature infants [1], and these parents are faced with great uncer- tainty about their own parental roles [2-4]. It may take longer for parents to adjust to the demands of a preterm birth, and it is therefore important to improve support given to families with premature infant, even after hospital discharge [5]. Transition from hospital to home can be moments of great expectations for the family [6], but it also can be an anxious time for parents of preterm infants [7-10]. Nurses have an essential role in working with families to create family-centered discharge processes [11]. Preparing and teaching parents is vital for the successful transition from hospital to home [12,13]. In this manner, support is essential for parents in caring for a prematurely born infant [4,14-17].

After homecoming, the preterm infants' health and quality of life depend on an optimal home environment with parents who can effectively respond to the infant's needs [18]. The lack of qualified support, as meeting skilled personnel with knowledge in neonatal care, is one of the most difficult issues faced by families during the first year of life of their prematurely born infant [19]. It is therefore of significance to improve support to families with preterm born infant after homecoming [5].

Advances in computer and telecommunication technologies are now allowing nurses to provide nursing care to patients in alternate care sites and remote geographic areas [20].

Within neonatal care, a program has been developed called "Baby CareLink". This allows families to have increased access to their infant and educational information during hospitalization and post-discharge. The project provides the opportunity to have videoconferences between the NICU and the family at home, which allows parents to see their infant and receive teaching and support from the staff [21].

Having access to distance-spanning health care can contribute to improve infant care, as the technology creates opportunities to bridge the distances between home and hospital. Thus, new forms of work emerge as an example is the development of the intervention program neonatal nursing care at home via videoconferencing. This study is part of a larger study aiming to investigate 
if real-time videoconferencing can be used as a tool for providing support to parents of preterm born infant after the families' homecoming. However, the purpose of this paper was to describe the development, planning and implementing of an internet-based intervention program for providing support to families with prematurely born infants.

\section{THE INTERNET-BASED INTERVENTION PROGRAM}

\subsection{Context for the Intervention}

The region where the study was carried out is situated in the northernmost county in Sweden. The county Norrbotten covers one-quarter $\left(98,249 \mathrm{~km}^{2}\right)$ of Sweden's surface area, and the county is sparsely settled, with most of the population of 250,000 living near the coast [22]. The intervention program was developed in collaboration between Luleå University of Technology and Norrbotten County Council and was realized at a neonatal intensive care unit (NICU). The large land area and the sparsely population provides unique possibilities for health professionals to use technology in supporting people in remote locations. Staff at the NICU, where the study took place, drawn attention to if use of real-time videoconferencing between the NICU and the families' home could be developed as a possible way to increase the support for the parents, thereby facilitate for the family after homecoming with their preterm-born infant. Contact was thereafter established between the University and the NICU, and discussion on the possibility of developing and using videoconferencing as a tool to support parents was thereby initiated. The development of the intervention program was based on the specific needs for families with preterm-born infant and on long-term experiences from related research by Öhrling and co-workers [2326].

Throughout the whole research process when developing the intervention program, ethical considerations were taken into account, and every possible effort was made to follow ethical guidelines in planning and implementation of the intervention. All the participants gave their informed consent to participate in this study. The study was approved by the Regional Ethical Review Board in Umeå, Sweden (Dnr. 05-085M).

\subsection{Overview of Methods}

The researchers took an active part in the development and planning of the intervention program. It was considered to be of significance to include nurses from the NICU as partners throughout the planning and implementation of the intervention and to give information to all personnel.
A total of 10 families participated in the intervention. The criteria for inclusion for parents were being parents to a preterm infant born below gestation week 34 and thereby needing care at a NICU. Further, both parents must agree to participate. They also must have access to broadband or ADSL from their home. All twenty nurses at the NICU participated in the intervention and ten of the nurses volunteered to be interviewed. The criteria for participation for nurses were being a Certified Pediatric Nurse (CPN), (i.e. registered nurse with specialized training in pediatric nursing), experience of working in a NICU and experience in the use of videoconferencing after being trained how to use the equipment.

Parents experiences were captured by interviews using a narrative approach $[27,28]$ and were conducted with the parents before and after they had used the videoconference system [29]. The CPNs also were interviewed twice, before testing and within a month after the project was ended [30]. Based on the interviews and notes made during the research process a qualitative content analysis $[31,32]$ was used to describe the development, planning and implementation of the intervention.

\subsection{Development and Planning}

The intervention program was designed to be an addition to the already existing care whereby the foremost intention was to provide parents with increased support and not for other purposes such as earlier discharge of the infant or any financial gains. The expectation was that this intervention program will be implemented as a normal part in the work at the NICU, if the results prove to be beneficial.

After parents have spent a long time at the NICU with their infant, most of the families go home with their infant on leave, before the infant finally is discharged from the unit. The length of that leave varies from a few days to several weeks and depends on the infants' medical condition and parental competence of taking care of their infant at home. Using the telephone for communicating with parents was (prior to the intervention) the common practice during families' initial stay at home.

It was desirable to include nurses in an early phase of project design, as they can advocate their specific needs. For being an empowering tool for the nursing profession, nurses as end users have to be involved in the early phase [33]. Two CPNs voluntarily notified their interest, and during the intervention, they took an active part in informing and supporting their colleagues at the NICU. They also were central in the intervention, providing a linkage between the researchers, the NICU staff and the parents. Great efforts were made in finding a suitable videoconferencing system. The criteria for arriving at the choice were as follows: good quality of sound and image, 
user-friendliness to make the system accessible regardless of previous knowledge (i.e., it must be easy to put it to use at home), and the equipment must be in accordance with the used system in the County Council, as we planned to use the data network run by the County Council, although with the necessary security clearance. With guidance from IT technicians from the County Council and the head nurse at the NICU, a videoconferencing system, Polycom VSX 3000, was found to be the most appropriate, it offers TV-like video and near CDquality audio. It is a completely full-featured integrated, all-in-one videoconferencing system including camera, display, stereo speakers, and microphones, with video conferencing over IP and ISDN networks. It was considered to facilitate for both parents and staff to use the same type of equipment at the NICU and in the families' home. Another important part of realizing the intervention program was to have a secure bridge between the hospital and the families' home, with the aim of ensuring the secrecy safeguard for the family. This secure bridge was installed and thereby was the communication between staff and parents locked for all those who not were admitted.

Before the intervention started, all NICU staff was given detailed information repeatedly. An easy-to-understand user's manual for both staff and parents were constructed. All nurses were trained on the use of videoconference equipment by IT technicians from the County Council. As mentioned earlier, two CPNs had a more active part; consequently, they received additional training for being able to educate and support their colleagues in the use of technology. Access to support from IT technicians was ensured to be available if problems arise. We believed it to be important to make the staff secure on the use of videoconferencing, as their attitude is transferred to the parents.

The phase of developing and planning the intervention took long time (Figure 1), which subsequently was found to have a significant impact on the implementation because most of the conditions were met. Consequently, considering the positive effects led to the possibility of the permanent use of videoconferencing after the project was concluded.

As shown in Figure 1, the intervention program was divided into phases, it is ended and implemented as a usual part in the work at the NICU.

\subsection{Implementation}

The intervention program took place over a period of one year and ten families used the videoconferencing equipment. Each family had the videoconference system cost-free on loan, and they were trained how to use the system prior to going home. The training was facilitated by having the same equipment at the NICU and in the family's home. Technical support was provided by IT technicians from the County Council. The equipment was easily installed by the parents themselves, by just connecting to the electric supply and broadband network. Parents must have broadband or ADSL, with 512 kbps speed for both parties, to ensure high quality. It was advantageous to have a public IP address through DHCP; otherwise, an IT technician was on call for support, by telephone or house visit, to give them an IP address. Three of the families needed technical support because of not having a dynamic IP address; however, this was easily solved by IT technicians via consultation by telephone. We recommended all families to bring the equipment home prior to homecoming, to ensure that the videoconferencing system was working well. Parents were encouraged to feel free to use the access day and night, whenever they needed or wanted. Contact was initiated and planned according to the families' individual needs and preferences. The total amount of contacts varied between the families, from 2 to about 30, the majority of the meetings were planned. The lengths of the time the families used the equipment varied from one week to three weeks. The length of the meeting lasted from a few minutes up to almost one hour. During the implementation the CPNs contacts with families via videoconferencing was added as a task in their daily work. Most of the meetings were planned, so the nurses could plan together with the families and specify a time that suits. When the meeting not was planned, nurses received a

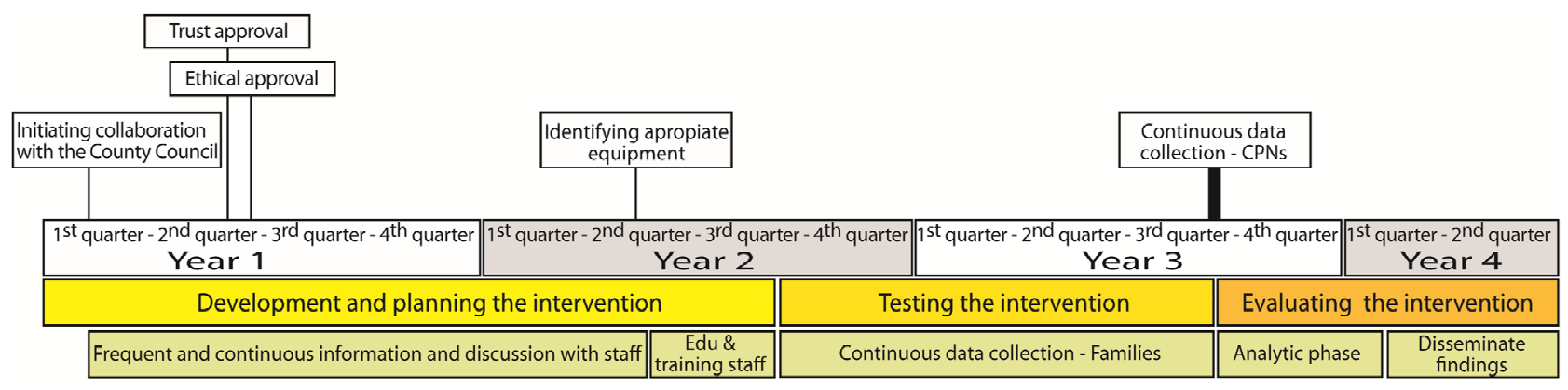

Figure 1. An overview of the intervention study. 
request from the family and needed to plan for the videoconferencing in collaboration with other nurses and duties. However, if it was considered to be urgent it was prioritized. Thereby they managed to balance request from families with their daily tasks (Figure 2).

\section{OUTCOME OF THE INTERVENTION PROGRAM}

\subsection{Supportive Meetings}

By having direct contact with staff around the clock, parents experienced security. Connection could be made if parents needed advice, had concerns, or just wanted to talk. The most important was to have this opportunity and not how often it was used. The use must be customized to families' needs and preferences.

Now I recommend all parents to take the chance if they get it, because it is by no doubt a security to have it. (Mother)

The use of videoconferencing makes it possible to give a sense of security to the family. (CPN)

Problems that emerged, such as for example feeding problems, could usually be solved by staff together with the family. Another advantage was that parents could talk together with a number of staff at the same time. The use of videoconferencing did not simplify the work for CPN, but it was a tool to improve support to the families. Videoconferencing allowed face-to-face supportive meetings despite the distance, and it was almost like a real-life encounter. Using the technique could be demanding; at times, the staff felt that they were being observed by the parents. The staff had to be more present during the meeting compared with when using the phone. The importance of communication with body language was stated. Other benefits include participation and involvement of both parents and an opportunity to support each other and it was possible for the staff to meet the whole family and the sibling was a natural part of the meeting.

I think that the greatest advantage is that we are able to look at each other instead of just be a one-on-one

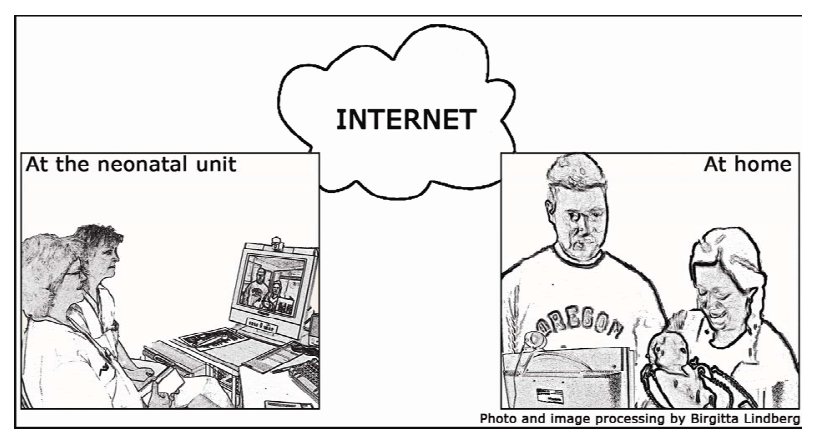

Figure 2. Videoconferencing between the family in their home and staff at the NICU. Reprinted with permission. telephone chat, enabling a full interactive discussion to follow. (Mother)

Although closeness was experienced, human contact could not completely be replaced.

Well it's important that it is a supplement as long as it is kept at that level so I do not think there are any special concerns as long it's not a replacement for anything it must be a supplement. (Father)

\subsection{An Empowering Tool}

Both seeing and hearing gave a completely different dimension; in that way, the staff could better assess the situation at home. It was possible to notice if the parents were worried or if the infant seemed to be unwell. By knowing that the staff could easily make an appraisal of the situation, parents felt safe.

You feel safer when you can see the one you are talking to and they (staff) can read me off and readily calm me down if there was anything bothering me. (Mother)

Providing information and instruction was eased by getting visual confirmation. For example with support from the nurse, parents could place a feeding tube in the infant's stomach. It has also proved possible to have an online consultation with the doctor at the NICU. Technology was mostly well functioning, but when the rather few technical problems occurred, it was for example when the picture was rather dark or a problem with the connection, the meetings were described as less fruitful. Families wanted to handle the videoconferencing by themselves and not be dependent on the staff. The videoconference system was experienced as user-friendly and quick to install.

You only have to read the instruction, you can't miss it and I'm rather non-technical. (Father)

The videoconference system was very easy to use and was mostly well-functioning. $(C P N)$

\subsection{Visionary Thinking}

The technology opens up other opportunities for use, for example, establishing a contact with child health services and between hospitals. It also can be a support system for families caring for children with chronic illness at home. Some of the parents used the technology to communicate with the rest of the family before coming home with the preterm infant, thereby siblings can be a natural part. It can also be used for communicating with grandparents. CPNs stated willingness to extend the use of videoconferencing. CPNs emphasized that before videoconferencing can be mainstreamed to neonatal practice, time is needed to incorporate the changes. However, in time, CPNs got used to videoconferencing. They were convinced that this technology must be a part of the upcoming care and a new standard 
within neonatal care. An opinion among all nurses was that videoconferencing was not being utilized to its full potential. Technology must be introduced earlier and taken into discussion as a normal element of what can be offered. Cooperation among different professional groups and making plans for families who return home are important.

The use of videoconferencing must be continued as it is supportive for the parents. (CPN)

\section{DISCUSSION}

\section{Application to Nursing Practice}

The purpose of this paper was to describe the development, planning and implementing of an internet-based intervention program for providing support to families with prematurely born infants. The intervention program resulted in incorporating videoconferencing permanently, as a tool to support families after coming home with their preterm born. According to Leonard [34], it is limited to the successful implementation of ICT in health care. As stated in a study [35], telehealth care developments often fail to progress beyond the trial stage and does not become part of routine service. Subsequently, a question arises: what made this intervention with ICT possible to implement. Probably a variety of factors has contributed to integrate videoconferencing into a new standard of neonatal care at the NICU where the intervention program was carried through. Fully what have made it possible are just speculations, but we want to highlight some of the critical factors necessary to make this project successful. Reflections over possible critical success factors for adoption of videoconferencing shall therefore be discussed. However, this study is not without weakness, but first and foremost we have chosen to focus on the positive aspects.

One of the most important factors was that the original idea came from staff at the NICU. The whole intervention program was influenced by the positive attitude from staff and their willingness to improve support to families. Because this intervention program is an empowering tool for the nursing profession, nurses as end-users have to be involved in the early phase of system design [33]. This was one of the reasons to include two nurses from the NICU as partners throughout the planning and the implementation of the intervention program. Therefore, an effective linkage between the researchers and the NICU staff was established, which was significant for an effective communication and for the involvement and participation of the whole staff. We also had regular meetings with all the staff so that they should be well prepared and well informed throughout the whole project. Identifying and finding suitable videoconferencing was cooperation between NICU staff, IT technicians, and the researchers. According to Ducharme, Beaudet, Legault, Kergoat, Lévesque and Caron [36] most researchers have developed programs without caregiver participation. The planning was in line with Ducharme et al. [36] thoughts about establishing a dialogue with caregivers with a view to tailoring intervention program to their needs.

Another significant factor was that daily work at a NICU is to take care of infants requiring high technology and advanced medical care, so working in an environment with technology was a natural part of their task, and new technology was frequently occurring. However, acceptance and use of ICT by nurses is dependent on personal technical skills, workplace culture, and the perceived benefit of the new system [33]. The workplace culture was permeated by a positive attitude to development, and also this intervention program was seen by staff as a positive challenge.

The results showed that nurses consider the use of technology as a natural part of health care in the future, which is consistent with other research showing that professionals generally find the technology to be acceptable and easy to integrate in the care delivery process [37]. However, the finding shows that time is needed to incorporate changes. Stated in a study [33], nurses felt more comfortable with the technology over time, and their satisfaction with this mode of care delivery increased with the number of virtual visits conducted. Professionals who are conducting telehealth interventions may need further experience in using the technology to feel comfortable with the approach [38], which is similar to our findings. Findings in a study [39] showed that even those participants who are unfamiliar with the technology are able to use it with little training and glean benefits. Nevertheless, the results showed that userfriendliness was of great significance, which also was paid attention to in the planning; so a great importance was put in finding suitable user-friendly equipment. According to Cone [40], it is essential to establish an environment that facilitates communication, where it is imperative that staff is present and attentive to the parents' needs.

As previously mentioned, this study is not without limitation. Above all, since this study involved only one NICU there is a weakness in the design and a need for increased research with more units involved. There is a need for long term evaluation for drawing better conclusions. The lack of financial follow up is a limitation in this study, but beneficial economic gains seem likely when using ICT based intervention program.

In conclusion, as evidenced by the findings, ICT must be taken into account in developing future care. It is a challenge to use different kinds of ICT and, at the same time, take advantage of the benefits. However, the use 
Table 1. Summary of important point for development of this intervention program for providing support to families with prematurely born infants.

- Plan the intervention based on individual needs from both the family and staffs perspective

- Involve staff as end users in the early phase of project design

- Regular meetings with all the staff

- Well-prepared and motivated staff

- Careful ethical considerations

- Trust approval

- Support from IT technicians in identifying suitable equipment and securing technical solutions

- Make the staff secure on the use of technology

- Construct user's manual for both staff and parents

- Appropriate documentation

- Continuous evaluation and assessment throughout the whole project

must be based on individual needs, with the intent to give optimal care. All from the start, it was clearly stated that the intervention program was designed to be an addition to the already existing care and must be considered as a complement to already existing health care system and not a substitute. However, by further developing distance-spanning health care, extended accessibility can be offered [41] for a variety of groups of people. According to Haux, Ammenwerth, Herzog and Knaup [42], our society is continuously influenced by modern ICT, and health care has greatly profited from this development. Over time, there is a need for further research on the effect of the work organization, financial aspects and the opinion of the staff after use for an extended time.

\section{ACKNOWLEDGEMENTS}

This study was supported by the Centre for Distance-Spanning Healthcare (CDH), Luleå University of Technology, Sweden, and the Norrbotten County Council, Sweden.

\section{REFERENCES}

[1] Fegran, L. and Helseth, S. (2009) The parent-nurse relationship in the neonatal intensive care unit contextCloseness and emotional involvement. Scandinavian Journal of Caring Sciences, 23, 667-673. doi:10.1111/j.1471-6712.2008.00659.x

[2] Franck, L.S., Cox, S., Allen, A. and Winter, I. (2005) Measuring neonatal intensive care unit-related parental stress. Journal of Advanced Nursing, 49, 608-615. doi:10.1111/j.1365-2648.2004.03336.x

[3] Holditch-Davis, D. and Miles, M.S. (2000) Mothers' stories about their experiences in the neonatal intensive care unit. Neonatal Network, 19, 13-21. doi:10.1891/0730-0832.19.3.13

[4] Wereszczak, J., Miles, M.S. and Holditch-Davis, D. (1997) Maternal recall of the neonatal intensive care unit.
Neonatal Network, 16, 33-40.

[5] Hummel, P. (2003) Parenting the high-risk infant. Newborn and Infant Nursing Reviews, 3, 88-92. doi:10.1016/S1527-3369(03)00035-7

[6] Rabelo, Z.S., Chaves, E.M.C.M., Cardoso, M.V.L.M.L. and Sherlock, M.S.M. (2007) Feelings and expectations of mothers of preterm babies at discharge. Acta Paulista de Enfermagem, 20, 333-337. doi:10.1590/S0103-21002007000300015

[7] Broedsgaard, A. and Wagner, L. (2005) How to facilitate parents and their premature infant for the transition home. International Nursing Review, 52, 196-203. doi:10.1111/j.1466-7657.2005.00414.X

[8] Holditch-Davis, D. and Miles, M.S. (1997) Parenting the prematurely born child. Annual Review of Nursing Research, 15, 33-34.

[9] Jackson, K., Ternestedt, B.M. and Schollin, J. (2003) From alienation to familiarity: Experiences of mothers and fathers of preterm infants. Journal of Advanced Nursing, 43, 120-129. doi:10.1046/j.1365-2648.2003.02686.x

[10] Kenner, C. and Lott, J.W. (1990) Parent transition after discharge from the NICU. Neonatal Network, 9, 31-37.

[11] Griffin, T. and Abraham, M. (2006) Transition to home from the newborn intensive care unit: Applying the principles of family-centered care to the discharge process. The Journal of Perinatal \& Neonatal Nursing, 20, 243249.

[12] Costello, A. and Chapman, J. (1998) Mothers' perceptions of the care-by-parent program prior to hospital discharge of their preterm infants. Neonatal Network, 17, 37-42.

[13] Scherf, R.F. and Reid, K.W. (2006) Going home: What NICU nurses need to know about home care. Neonatal Network, 25, 421-425. doi:10.1891/0730-0832.25.6.421

[14] Boonmee, J. and Pickler, R.H. (2005) Transition of preterm infants from hospital to home. Neonatal Intensive Care, 18, 22-25.

[15] Hughes, M., McCollum, J., Sheftel, D. and Sanchez, G. (1994) How parents cope with the experience of neonatal intensive care. Children's Health Care, 23, 1-14. doi:10.1207/s15326888chc2301_1

[16] Lindberg, B., Axelsson, K. and Öhrling, K. (2007) The birth of premature infants: Experiences from the fathers' perspective. Journal of Neonatal Nursing, 13, 142-149. doi:10.1016/j.jnn.2007.05.004

[17] Lindberg, B. and Öhrling, K. (2008) Experiences of having a prematurely born infant from the perspective of mothers in Northern Sweden. International Journal of Circumpolar Health, 67, 461-471. doi:10.3402/ijch.v67i5.18353

[18] Howland, L.C. (2007) Preterm birth: Implications for family stress and coping. Newborn and Infant Nursing Reviews, 7, 14-19. doi:10.1053/j.nainr.2006.12.008

[19] Mai, D. and Wagner, L. (2005) “Home early program”Experiences of parents to premature infant's one year after discharge. Vård i Norden, 25, 60-63. 
[20] Schlachta-Fairchild, L. (2001) Telehealth: A new venue for health care delivery. Seminars in Oncology Nursing, 17, 34-40. doi:10.1053/sonu.2001.20417

[21] Gray, J.E., Safran, C., Davis, R.B., Pompilio-Weitzner, G., Stewart, J.E., Zaccagnini, L. and Pursley, D. (2000) Baby CareLink: Using the internet and telemedicine to improve care for high-risk infants. Pediatrics, 106, 13181324. doi:10.1542/peds.106.6.1318

[22] The County Administrative Boards of Norrbotten. http://www.regionfakta.com

[23] Lindberg, I., Christensson, K. and Öhrling, K. (2007) Parents' experiences of using videoconferencing as a support in early discharge after childbirth. Midwifery, 25, 357-365. doi:10.1016/j.midw.2007.06.002

[24] Lindberg, I., Öhrling, K. and Christensson, K. (2007) Midwives' experience of using videoconferencing to support parents who were discharged early after childbirth. Journal of Telemedicine and Telecare, 13, 202-205. doi:10.1258/135763307780908102

[25] Nyström, K. and Öhrling, K. (2006) Parental support: Mothers' experience of electronic encounters. Journal of Telemedicine and Telecare, 12, 194-197. doi:10.1258/1357633067774488726

[26] Nyström, K. and Öhrling, K. (2008) Electronic encounters: Fathers' experiences of parental support. Journal of Telemedicine and Telecare, 14, 71-74. doi:10.1258/jtt.2007.070605

[27] Mishler, E.G. (1986) Research interviewing: Context and narrative. Harvard University Press, Cambridge.

[28] Sandelowski, M. (1991) Telling stories: Narrative approaches in qualitative research. Image-The Journal of Nursing Scholarship, 23, 161-166. doi:10.1111/j.1547-5069.1991.tb00662.x

[29] Lindberg, B., Axelsson, K. and Öhrling, K. (2009) Taking care of their baby at home but with nursing staff as support: The use of videoconferencing in providing neonatal support to parents of preterm infants. Journal of Neonatal Nursing, 15, 47-55. doi:10.1016/j.jnn.2009.01.004

[30] Lindberg, B., Axelsson, K. and Öhrling, K. (2009) Experience with videoconferencing between a neonatal unit and the families' home from the perspective of certified paediatric nurses. Journal of Telemedicine and Telecare, 15, 275-280. doi:10.1258/jtt.2009.090112

[31] Baxter, L.A. (1991) Content analysis. In: Montgomery, B.M. and Duck, S. Eds., Studying Interpersonal Interaction, The Guilford Press, New York, London, 239-254.
[32] Cantanzaro, M. (1988) Using qualitative analytic techniques. In: Woods, N.F. and Cantanzaro, M. Eds., Nursing Research, Theory and Practice, Mosby, St. Louis., 437-456.

[33] Courtney, K.L., Demiris, G. and Alexander, G.L. (2005) Information technology: Changing nursing processes at the point-of-care. Nursing Administration Quarterly, 29, 315-322.

[34] Leonard, K.J. (2004) Critical success factors relating to healthcare's adoption of new technology: A guide to increasing the likelihood of successful implementation. Electronic Healthcare, 2, 72-81.

[35] Finch, T.L., Mort, M., Mair, F.S. and May, C.R. (2008) Future patients? Telehealthcare, roles and responsibilities. Health \& Social Care in the Community, 16, 86-95. doi:10.1111/j.1365-2524.2007.00726.x

[36] Ducharme, F., Beaudet, L., Legault, A., Kergoat, M.J., Lévesque, L. and Caron, C. (2001) Development of an intervention program for Alzheimer's family caregivers following diagnostic disclosure. Clinical Nursing Research, 8, 44-67.

[37] Demiris, G., Edison, K. and Schopp, L.H. (2004) Shaping the future: Needs and expectations of telehealth professionals. Telemedicine Journal and E-Health, 10, 60-63. doi:10.1089/1530562042631921

[38] Schopp, L., Johnstone, B. and Merrell, D. (2000) Telehealth and neuropsychological assessment: New opportunities for psychologists. Professional Psychology, Research and Practice, 31, 179-183. doi:10.1037/0735-7028.31.2.179

[39] Liss, H.J., Glueckau, R.L. and Ecklund-Johnson, E.P. (2002) Research on telehealth and chronic medical conditions: Critical review, key issues, and future directions. Rehabilitation Psychology, 47, 8-30. doi:10.1037/0090-5550.47.1.8

[40] Cone, S. (2007) The impact of communication and the neonatal intensive care unit environment on parent involvement. Newborn and Infant Nursing Reviews, 7, 33-38. doi:10.1053/j.nainr.2006.12.006

[41] Jenkins, R.L. and White, P. (2001) Telehealth advancing nursing practice. Nursing Outlook, 49, 100-105. doi:10.1067/mno.2001.111933

[42] Haux, R., Ammenwerth, E., Herzog, W. and Knaup, P. (2002) Health care in the information society. A prognosis for the year 2013. International Journal of Medical Informatics, 66, 3-21. doi:10.1016/S1386-5056(02)00030-8 